\title{
Lameness in a rabbit
}

\author{
Christopher J. Gibson, VMD ${ }^{1,2}$ \& Thomas M. Donnelly, DVM ${ }^{2}$
}

An 18-month-old, 2.3-kg, New Zealand white, intact female rabbit was presented to the Exotic Pet service at Tufts University, Cummings School of Veterinary Medicine, for a 3-day history of anorexia, decreased urine and stool output and right hind limb lameness characterized by non-weightbearing.

The exotic pet veterinarians examined the rabbit and palpated a $2.0-\mathrm{cm}$-diameter mass on the proximal aspect of the right femur. In addition, they noted the rabbit had pale mucous membranes. They carried out a neurological examination to determine the cause of the lameness, and the results were within normal limits except for splaying of the forelimbs.

The clinicians then took whole-body ventrodorsal and left lateral radiographs of the rabbit, which showed a diffuse pulmonary micronodular interstitial pattern throughout the lung parenchyma, characterized by diffusely distributed multiple, rounded, punctuated mineral opacities (Fig. 1). Throughout the abdomen and subcutaneous tissue, we observed diffusely located, multiple soft tissue and mineral opacities with ill-defined margins. Radiographic examination of the right hind limb showed possible fracture with exuberant amorphous periosteal reaction of the proximal diaphysis of the right femur and increased right femoral bone density (Fig. 2).

The owners did not wish to pursue further diagnostics and elected to have the rabbit euthanized, allowing the pathology service

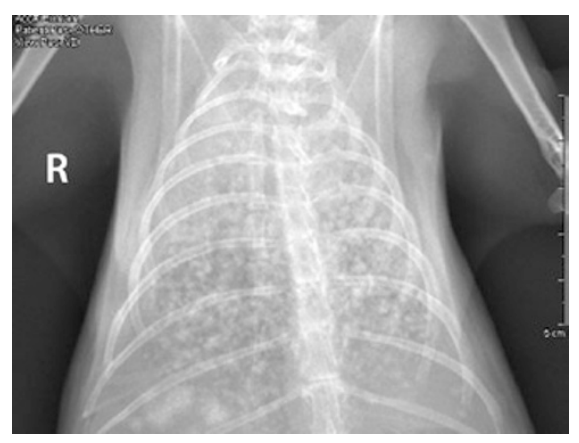

FIGURE 1 | Ventrodorsal radiograph of the thorax of an 18-month-old, intact female rabbit. There is a diffuse micronodular interstitial pattern characterized by diffusely distributed multiple, rounded, punctuated mineral opacities.

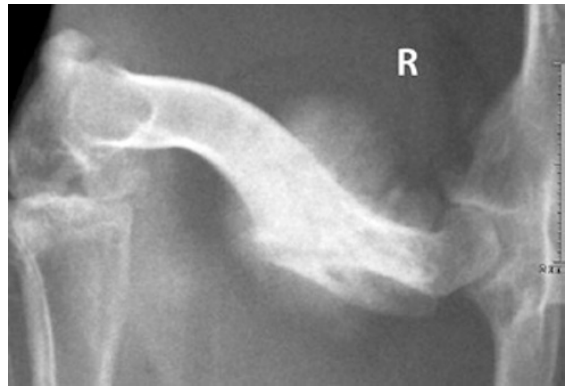

FIGURE 2 | Radiograph of the right femur of the same rabbit shown in Figure 1. There is a possible pathological fracture with exuberant amorphous periosteal reaction of the proximal diaphysis.

to necropsy the rabbit. On post-mortem examination, there was approximately $20 \mathrm{ml}$ of opaque, brown-red watery fluid present in the pleural cavity. All the lung lobes were diffusely expanded and effaced by

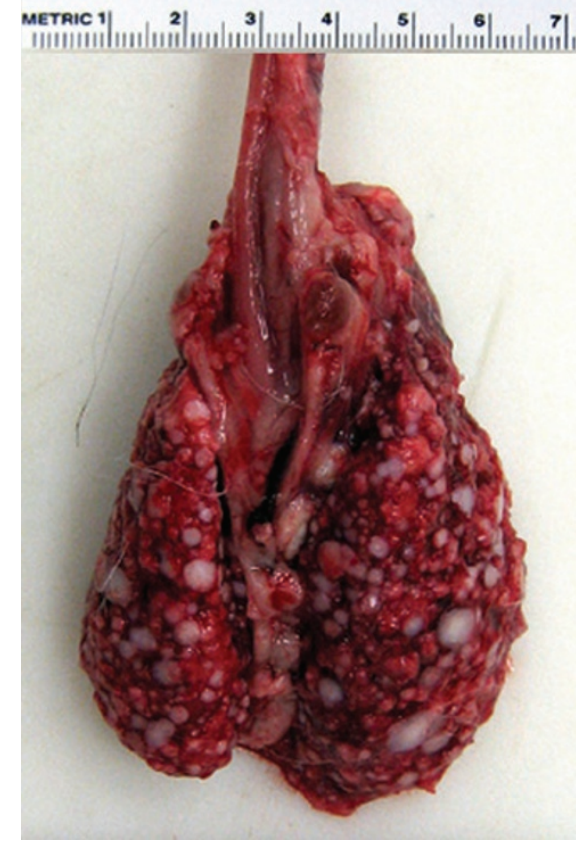

FIGURE 3 | The dissected lungs of the rabbit shown in Figure 1. The lung lobes are expanded and show numerous multifocal, variable-sized, pale tan to white, raised, round, nodular masses.

multifocal, variably sized, pale tan to white, raised, round, nodular masses ranging in diameter from $1 \mathrm{~mm}$ to $5 \mathrm{~mm}$ (Fig. 3).

Given the clinical history, physical examination, radiographs and necropsy information, what are your differential diagnoses?

\section{What's your diagnosis?}

\footnotetext{
${ }_{1}^{1}$ Department of Pharmacology and Toxicology, Rutgers University Ernest Mario School of Pharmacy and Environmental and Occupational Health Sciences Institute, Piscataway, NJ. ${ }^{2}$ Cummings School of Veterinary Medicine, Tufts University, North Grafton, MA. Correspondence should be addressed to C.J.G. (gibson@eohsi.rutgers.edu).
} 